\title{
Detraining attenuation during the COVID-19 pandemic: practical considerations for home- based strength and power training
}

\begin{abstract}
Atenuação do destreinamento durante a pandemia de COVID-19: considerações práticas para o treinamento de força e potência em ambiente doméstico
\end{abstract}

\author{
Lucas Guimarães-Ferreira ${ }^{1,3}$, Danilo Salles Bocalini ${ }^{2,3}$ \\ 1. Muscle Physiology and Human Performance Research Group, Center of Physical Education, Federal University of Espirito \\ Santo, Vitória/ES, Brazil. \\ 2. Translational Physiology Applied to Health, Sport and Human Performance Research Group, Center of Physical Education, \\ Federal University of Espirito Santo, Vitória/ES, Brazil. \\ 3. Postgraduate Program in Physical Education, Center of Physical Education, Federal University of Espirito Santo, Vitória/ES,
}

Brazil.

\begin{abstract}
The COVID-19 pandemic that scattered across the world in 2020 has required collective action to control the transmission of the disease. Among the measures, social distancing has been widely adopted, aiming to reduce contact and people gathering. With the limited access to training places that have equipment and a variety of loads for strength and power training, alternative strategies to be carried out in the domestic environment are important for maintaining physical conditioning and mitigating the deleterious effects of detraining. Based on the available scientific literature, this article presents practical recommendations for strength training in the home environment. It is recommended to perform exercises that employ self-body weight, household items and, when available, dumbbells and elastic bands. Whenever using low loads (30-50\% of 1 repetition maximum), performing the sets until the concentric failure seems to be necessary to optimize gains in strength and muscle mass. The practice of physical exercises should be performed on most days of the week ( $>5$ days/week), combined with domestic and leisure activities that involve the movement of the whole body. For maintenance and / or development of muscle power, ballistic movements must be included, in the presence or absence of external loads.
\end{abstract}

Key-words: Strength training, Power, Detraining, COVID-19.

\section{RESUMO}

A pandemia de COVID-19 que se espalhou por todo o mundo em 2020 demandou ações coletivas para controle da transmissão da doença. Dentre as medidas adotadas, o distanciamento social vem sendo amplamente adotado, visando a redução do contato e aglomeração de pessoas. Com a limitação ao acesso a locais de treinamento que dispõe de equipamentos e variedade de carga para o treinamento de força e potência, estratégias alternativas para realização no ambiente doméstico se fazem importante para manutenção do condicionamento físico e atenuação dos efeitos deletérios do destreinamento. Utilizando como base a literatura científica disponível, 
o presente artigo apresenta recomendações práticas para o treinamento de força no ambiente doméstico. Recomenda-se a utilização de exercícios que utilizam o peso do próprio corpo, itens domésticos e, quando disponíveis, halteres e bandas elásticas. Ao se utilizar baixas cargas (30-50\% de 1 repetição máxima), a realização das séries até a falha concêntrica parece ser necessária para otimizar os ganhos de força e massa muscular. A prática de exercícios físicos deve ser realizada na maioria dos dias da semana (>5 dias/semana), combinada a atividades domésticas e de lazer que envolvam a movimentação de todo o corpo. Para manutenção e/ou desenvolvimento da potência muscular, movimentos balísticos devem ser incluídos, com ou sem cargas externas.

Palavras-chave: Treinamento de força, Potência, Destreinamento, COVID-19.

\section{Introduction}

COVID-19 is an infectious respiratory disease caused by the SARS-CoV-2 coronavirus that became a pandemic in a short period of time during the year 2020 [1]. Until April 13, 2020, 1.9 million cases were registered, with 118 thousand deaths worldwide [2]. Among the various preventive measures adopted by the World Health Organization and local governments, social distancing has been shown to be effective in preventing the spread of the disease [3]. During this delicate period, many cities in the world banned access to closed places, including training spaces, such as sports clubs and gyms, given that the crowding of people represents a threat.

The maintenance of physical fitness during the period of social distancing, both from the perspective of health and sports performance, is of great importance. Thus, this article aimed to discuss, through a narrative review of the scientific literature, alternatives for maintaining neuromuscular function without needing large and/or high cost equipment to be performed in the home environment. Finally, we summarize possible strategies and practical recommendations for home-based exercise during social isolation and distancing currently adopted.

\section{Detraining}

When physical training is interrupted, the adaptations obtained previously are reversed, until reaching the pre-training values. This phenomenon is known as detraining $[4,5]$. However, once a certain training adaptation has been achieved, considerably less training stimulus is required to maintain it, when compared to that necessary to develop it in the first place [6]. This means that even when there is a reduction in the training stimulus, but not its complete interruption, it seems possible to attenuate or even prevent reductions in physical conditioning.

A study with elderly participants showed that a strength training program for 12 weeks results in an increase in muscle strength and power by 10 to $36 \%$ [7]. In contrast, detraining for the same 12-week period led to a 5 to $15 \%$ reduction in the same parameters. These results suggest that when analyzing the temporal pattern of training and detraining, it is possible that the latter occurs at a slower pace, allowing a partial maintenance of the gains obtained from previous strength training after a detraining period of the same duration. Such 
findings were corroborated in young adults by Psilander et al. [8]. Men and women underwent 10 weeks of a strength training program, which resulted in an increase in the cross-sectional area of muscle fibers $(+17 \%)$, muscle thickness $(10 \%)$ and strength $(+20 \%)$. After 20 weeks of detraining, the diameter of the muscle fibers and the muscle volume returned to pre-training values, but muscle strength was partially remained (at $\sim 60 \%$ ). The motor learning effect involved in strength training seems to be maintained for a longer time during detraining when compared to the morphological changes of the muscle fibers.

A short period of detraining may be sufficient to develop detrimental changes in neuromuscular function in athletes. 2 weeks of complete interruption of training in 12 athletes resulted in a $19.2 \%$ reduction in type II muscle fibers area, although type I fiber area remained unchanged. The performance in bench press, squat and vertical jump decreased by $-1.7,-0.9$ and $-1.2 \%$, respectively. Although changes in strength and power have not shown statistical significance, they deserve attention in view of the short detraining time and the importance that small changes can present for high-performance athletes. When compared to strength, muscle power seems to be affected earlier during detraining. In moderately strength-trained men, 6 weeks of detraining caused a significant reduction in power, without significant changes in maximum strength measured with the 1-maximum repetition test (1RM) [9].

Considering the temporary nature of social distancing, with a probable duration of a few weeks, it is expected that after this period practitioners, athletes or not, will return to the strength training facilities. Individuals with experience in strength training, after a detraining period, seem to present gains in muscle strength and hypertrophy at a higher pace when compared to untrained individuals [10]. This phenomenon is commonly known as "muscle memory", which in the past was attributed to motor learning and intermuscular coordination, (neural factors) [11]. More recently, however, some authors have suggested molecular mechanisms involved in this process that may involve the number of nuclei in the muscle cells ("myonuclear domain") [12] and/or epigenetic changes in the muscle cells [13].

With the limitation on access to large equipment and a variety of weights and dumbbells, it is necessary to seek valid alternatives for maintaining physical fitness and mitigating the deleterious effects of detraining during this temporary period. These issues are presented and discussed in the following sections.

\section{Resistance training with low loads}

It is common, even in textbooks and technical/scientific position stands on strength and conditioning, to recommend strength exercises with a load equivalent to 6-12 repetitions to optimize muscle hypertrophy $[14,15]$. This idea, however, has been questioned and new studies have brought to light new possibilities. An investigation published in 2010 by Burd et al. [16] was important for breaking this paradigm. Fifteen active men performed 4 sets of knee extension with 3 load/repetition schemes: 1) $90 \%$ of 1 RM until concentric failure; 2) $30 \%$ of 1 RM with volume equalized to the previous condition (without reaching volitional failure); and 3) $30 \%$ of $1 \mathrm{RM}$ until concentric failure. The authors measured muscle protein synthesis rates before and after 4 and 24 hours of the resistance exercise session. It was demonstrated that myofibrillar protein 
synthesis was elevated after 4 hours in the condition $30 \%$ and $90 \%$ of 1 RM until failure, but only with $30 \%$ of 1 RM until concentric failure after $24 \mathrm{~h}$. Cell signaling proteins involved in protein synthesis (Akt/mTOR pathway) were activated in all conditions when compared to the resting situation.

Burd et al. [16] investigated the acute response of muscle protein synthesis in response to a session of resistance exercise. However, the chronic effects of resistance training at different intensities and its effects on skeletal muscle hypertrophy were still to be determined. To fill this gap, the same research group evaluated the effects of a 12-week strength training program using $75-90 \%$ of 1 RM or $30-50 \%$ of 1 RM on muscle hypertrophy and strength, with all series being performed until the concentric failure. Fat free mass and cross-sectional area of muscle fibers increased significantly in response to training, with no differences between conditions. Muscular strength measured as 1RM load also increased significantly in both conditions without differences between them, except for the bench press exercise, where it was superior in the high load group. The results of subsequent investigations [17-20] and the meta-analysis conducted by Schoenfeld et al. [21] allow us to conclude that while the use of high loads (> 70\% of $1 \mathrm{RM}$ ) seems to promote a superior stimulus for strength gains, the same cannot be said about skeletal muscle hypertrophy.

The necessity or not to perform resistance exercise sets until the concentric failure was also investigated. Concentric failure can be defined as the inability to perform correctly an additional repetition of a given exercise. If the practitioner is not able to continue performing a particular exercise without external assistance or without the correct form, he has reached the concentric failure. In the fitness and bodybuilding circles, it is a common sense that to maximize adaptations to training, that is to maximize gains in strength and muscle hypertrophy, it would be necessary to perform resistance exercises until concentric failure. But do scientific studies corroborate this statement?

A systematic review with meta-analysis conducted by Davies et al. [22] included 8 studies that addressed this issue and concluded that, to maximize gains in muscle strength, it does not seem necessary. Such a meta-analysis did not evaluate muscle hypertrophy, but as pointed out by Schoenfeld and Grgic [23], performing sets until concentric failure can be part of a training program, however they are not necessary to optimize the hypertrophic response. Additionally, they also emphasize that especially when training at high weekly frequency (4 or more days), the inclusion of exercises performed until failure can have a negative impact on impairing recovery between training sessions. In fact, one of the deleterious effects to perform all sets until the concentric failure is the total session volume reduction (and consequently the total weekly volume), when compared to a set that the individual finishes before reaching failure $[24,25]$.

While most of the studies assessing training to failure or not used higher loads, generally greater than $70 \%$ of $1 \mathrm{RM}$, recent studies have deepened the investigation with other loading schemes. In order to determine whether sets should be performed up to the concentric failure to promote muscle hypertrophy with the use of low loads, Lasevicus et al. [17] investigated 25 untrained men performing 8 weeks of a resistance exercise program in four different conditions: low loads with or without concentric failure ( 34.4 and $~ 19.6$ repetitions per set, respectively) and high loads with or without concentric failure $(\sim 12.4$ and $\sim 6.7$ repetitions per set, respectively). The results showed that al- 
though maximum strength increased significantly only with the use of high loads, quadriceps muscle hypertrophy was similar between conditions, but only when low loads sets were performed until the concentric failure. The study employed individuals with no experience in strength training, but other studies corroborate these findings in trained individuals $[20,26]$.

In conclusion, when using low loads (30-60\% 1RM), performing sets to concentric failure seems to be necessary to improve strength and increase muscle mass. When high loads are used, however, high-threshold motor units are already recruited, and training to failure does not appear to bring an additional benefit $[23,27]$. In fact, with high loads the failure can even be counterproductive, since it can result in a total training volume reduction, greater fatigue, necessity for longer recovery time between training sessions and even higher risk for the development of overtraining [23-25].

\section{Resistance training using the body weight and elastic bands}

At home, in general, access to training equipment or to a variety of weights and heavy dumbbells is limited. Thus, the use of light loads with dumbbells, exercises using the body weight, elastic bands or household items can be a valid alternative to generate resistance in a strength training program. For example, Kikuchi and Nakazato [28] evaluated the effects of a resistance training program for 8 weeks with a frequency of 2 days / week using exercise with their own body weight (push-ups) with a load equivalent to $40 \%$ of 1 RM on muscle strength and hypertrophy. The training with body weight protocol resulted in a significant increase in strength and thickness of the pectoris and triceps muscles at the same magnitude as observed when bench press was performed using the same relative intensity.

Elastic bands are often used in conjunction with weights and dumbbells in the so-called training with variable resistance [29]. Such method is based on the use of elastic bands to alter the external resistance during the exercise at the entire range of motion [30]. The use of elastic bands alone has also been studied, but mainly in more vulnerable populations, such as the elderly or patients in a hospital environment [31-33]. For example, Orange et al. [34] demonstrated that 4 weeks of a resistance training program using elastic bands and exercises with body weight with a weekly frequency of 3 days resulted in increased functional capacity in middle-aged men. However, studies that evaluated the effects of training using only elastic bands in healthy young adults, athletes or not, are scarcer.

A study with young female handball players evaluated the effect of a training program using elastic bands for 9 weeks, with a weekly frequency of 3 days/week [35]. The program consisted of 6 exercises involving trunk and lower and upper limbs, performed at 3 sets of 6 to 10 repetitions per exercise, with high execution speed. Power, pitch speed and agility were significantly improved at the end of the training period. Similarly, Mascarin et al. [36] demonstrated that strength training using elastic bands for 6 weeks during the pre-season in handball athletes resulted in improved muscle power and throwing performance. Buskard et al. [37] developed a method to determine the optimal training load with elastic bands, in order to be used for athletes in the development of muscle power. The authors concluded that its use can be adopted by coaches to improve athletes' muscular power, especially when the use of free weights 
and training equipment is limited.

Therefore, although limited studies have evaluated the effects of exercises using the body weight or elastic bands in healthy young adults, such strategy seems to be effective in mitigating or preventing the deleterious effects of detraining when the access to free weights, dumbbells and strength training equipment is limited.

\section{Further considerations}

Training frequency is an important variable in every strength training program. Studies have been carried out to determine whether there is an ideal weekly frequency to maximize gains in strength and muscle hypertrophy, as summarized in recent meta-analyzes [38,39]. In general, there seems to be no differences for muscle hypertrophy when total weekly training volume is equalized. In other words, the effects of performing 30 sets of a given muscle group in a week divided into 2 or 3 days of training ( 15 and 10 sets per session, respectively), seems to promote the same adaptations. It is important, however, to emphasize that performing a high training volume in one session will require longer recovery periods. Therefore, it may be more feasible to increase weekly frequencies, rather than increase the number of sets per session in order to promote a higher weekly training volume. Regarding muscle strength, higher training frequencies seem to be associated with greater gains, especially in younger individuals [38]. Considering the limitation of space and training equipment for physical exercise, we recommend the adoption of high training frequency ( $>5$ times/week) during the period of social distancing, alternating with aerobic exercises whenever possible, and with domestic and leisure activities involving the movement of the whole body.

In the midst of the current COVID-19 pandemic contact among people should be avoided. Thus, face-to-face guidance by training professionals is not possible. However, whenever necessary and especially for beginners with no previous training experience, it is recommended alternatives for physical exercise prescription with no close contact between coach and clients. A study with middle-aged adults (average of 53.6 years) demonstrated that there were no differences in the effects of a home-based physical training program with or without in person supervision [34]. It is important to note that the unsupervised group received face-to-face instructions for carrying out the prescribed exercises at the beginning of the intervention. Remote monitoring of practitioners who have the basic knowledge of resistance exercises can be a valid alternative and should be encouraged when the professional face-to-face intervention is not possible. 


\section{General recommendations}

Based on the discussion above, we now address general recommendations for home-based strength training:

- Social distancing prevents contact with contaminated droplets, even from asymptomatic persons. Therefore, the access to training facilities, such as sports clubs and gyms is limited. It is important, therefore, to adopt alternative training strategies that can be implemented at home in order to mitigate or prevent the harmful effects of detraining.

- Exercises using body weight or with household items can be used as an external load to promote resistance. If available, it is also recommended to use dumbbells and elastic bands to implement the training load;

- If it is not possible to use high loads, resistance exercise sets should be performed to concentric failure;

- Proper posture and correct technique during exercise movements must be prioritized, especially when performed to (or close to) concentric failure. When it is not possible to perform more repetitions with the correct form, the set must be interrupted, providing an adequate rest period prior the next set.

- To maintain muscle power, ballistic movements must be included, with or without external loads;

- Physical exercise should be performed preferably at a frequency of $>5$ days/week. In addition to exercise sessions, it is important to avoid sedentary behavior as much as possible, performing domestic and leisure activities that involve whole-body movements.

- Special attention should be given to nutrition in order to optimize training adaptations. Nutritional recommendations are beyond the scope of this manuscript, but it is highly recommended to readers to access good reviews on this topic $[40,41]$.

- Monitoring by trained professionals is advisable, even if face-to-face attendance is not possible. It is recommended to use online tools, via text, audio and/or video, for professional guidance.

\section{Acknowledgements}

The authors are thankful to the Espírito Santo Research Foundation (no 84417625/2018). Funding had no influence on the preparation and publication of the current manuscript.

\section{References}

1. Huang H, Fan C, Li M, Nie H-L, Wang F-B, Wang H et al. COVID-19: A call for physical scientists and engineers. ACS Nano 2020. https://doi.org/10.1021/acsnano.0c02618

2. Worldometer - real time world statistics. Worldometer n.d. http://www.worldometers.info/ [accessed April 13, 2020].

3. Gasmi A, Noor S, Tippairote T, Dadar M, Menzel A, Bjørklund G. Individual risk management strategy and potential therapeutic options for the COVID-19 pandemic. Clin Immunol Orlando Fla 2020. https://doi.org/10.1016/j.clim.2020.108409

4. Mujika I, Padilla S. Detraining: loss of training-induced physiological and performance 
adaptations. Part II: Long term insufficient training stimulus. Sports Med 2000;30(3):145-54. https://doi.org/10.2165/00007256-200030030-00001

5. Mujika I, Padilla S. Muscular characteristics of detraining in humans. Med Sci Sports Exerc 2001;33(8):1297-303. https://doi.org/10.1097/00005768-200108000-00009

6. MacDougall JD, Sale D. The physiology of training for high performance. OUP Oxford; 2014. 7. Blocquiaux S, Gorski T, Van Roie E, Ramaekers M, Van Thienen R, Nielens $H$ et al. The effect of resistance training, detraining and retraining on muscle strength and power, myofibre size, satellite cells and myonuclei in older men. Exp Gerontol 2020;133:110860. https://doi.or$\mathrm{g} / 10.1016 /$ j.exger.2020.110860

8. Psilander N, Eftestøl E, Cumming KT, Juvkam I, Ekblom MM, Sunding K et al. Effects of training, detraining, and retraining on strength, hypertrophy, and myonuclear number in human skeletal muscle. J Appl Physiol 2019;126(6):1636-45. https://doi.org/10.1152/japplphysiol.00917.2018

9. Kraemer WJ, Koziris LP, Ratamess NA, Hakkinen K, Triplett-Mcbride NT, Fry AC, et al. Detraining produces minimal changes in physical performance and hormonal variables in recreationally strength-trained men. J Strength Cond Res 2002;16(3):373-82.

10. Staron RS, Leonardi MJ, Karapondo DL, Malicky ES, Falkel JE, Hagerman FC et al. Strength and skeletal muscle adaptations in heavy-resistance-trained women after detraining and retraining. J Appl Physiol 1991;70(2):631-40. https://doi.org/10.1152/jappl.1991.70.2.631

11. Rutherford OM, Jones DA. The role of learning and coordination in strength training. Eur J Appl Physiol 1986;55(1):100-5. https://doi.org/10.1007/bf00422902

12. Gundersen K. Muscle memory and a new cellular model for muscle atrophy and hypertrophy. J Exp Biol 2016;219(pt 2):235-42. https://doi.org/10.1242/jeb.124495

13. Sharples AP, Stewart CE, Seaborne RA. Does skeletal muscle have an 'epi'-memory? The role of epigenetics in nutritional programming, metabolic disease, aging and exercise. Aging Cell 2016;15(4):603-16. https://doi.org/10.1111/acel.12486

14. American College of Sports Medicine. American College of Sports Medicine position stand. Progression models in resistance training for healthy adults. Med Sci Sports Exerc 2009;41(3):687708. https://doi.org/10.1249/MSS.ob013e3181915670

15. Baechle TR, Earle RW. Essentials of strength training and conditioning. Human Kinetics; 2008.

16. Burd NA, West DWD, Staples AW, Atherton PJ, Baker JM, Moore DR et al. Low-load high volume resistance exercise stimulates muscle protein synthesis more than high-load low volume resistance exercise in young men. PloS One 2010;5(8):e12033. https://doi.org/10.1371/journal. pone. 0012033

17. Lasevicius T, Schoenfeld BJ, Silva-Batista C, Barros T de S, Aihara AY, Brendon H et al. Muscle failure promotes greater muscle hypertrophy in low-load but not in high-load resistance training. J Strength Cond Res (in press) 2019. https://doi.org/10.1519/JSC.0000000000003454

18. Mitchell CJ, Churchward-Venne TA, West DWD, Burd NA, Breen L, Baker SK et al. Resistance exercise load does not determine training-mediated hypertrophic gains in young men. J Appl Physiol Bethesda 2012;113(1):71-7. https://doi.org/10.1152/japplphysiol.00307.2012.

19. Ogasawara R, Loenneke JP, Thiebaud RS, Abe T. Low-load bench press training to fatigue results in muscle hypertrophy similar to high-load bench press training. Int J Clin Med 2013;4(20):114-21. https://doi.org/10.4236/ijcm.2013.42022.

20. Schoenfeld BJ, Peterson MD, Ogborn D, Contreras B, Sonmez GT. Effects of low- vs. high-load resistance training on muscle strength and hypertrophy in well-trained men. J Strength Cond Res 2015;29(10):2954-63. https://doi.org/10.1519/JSC.0000000000000958

21. Schoenfeld BJ, Grgic J, Ogborn D, Krieger JW. Strength and hypertrophy adaptations between low- vs. high-load resistance training: a systematic review and meta-analysis. J Strength Cond Res 2017;31(12):3508-23. https://doi.org/10.1519/JSC.0000000000002200

22. Davies TB, Kuang K, Orr R, Halaki M, Hackett D. Effect of movement velocity during resistance training on dynamic muscular strength: a systematic review and meta-analysis. Sports Med 2017;47(8):1603-17. https://doi.org/10.1007/s40279-017-0676-4

23. Schoenfeld BJ, Grgic J. Does training to failure maximize muscle hypertrophy? Strength Cond J 2019;41(5):108-13. https://doi.org/10.1519/SSC.0000000000000473 
24. Morán-Navarro R, Pérez CE, Mora-Rodríguez R, de la Cruz-Sánchez E, González-Badillo JJ, Sánchez-Medina L et al. Time course of recovery following resistance training leading or not to failure. Eur J Appl Physiol 2017;117(12):2387-99. https://doi.org/10.1007/s00421-017-3725-7

25. Zourdos MC, Klemp A, Dolan C, Quiles JM, Schau KA, Jo E et al. Novel resistance training-specific rating of perceived exertion scale measuring repetitions in reserve. J Strength Cond Res 2016;30(1):267-75. https://doi.org/10.1519/JSC.0000000000001049

26. Morton RW, Oikawa SY, Wavell CG, Mazara N, McGlory C, Quadrilatero J et al. Neither load nor systemic hormones determine resistance training-mediated hypertrophy or strength gains in resistance-trained young men. J Appl Physiol 2016;121(1):129-38. https://doi.org/10.1152/ japplphysiol.00154.2016

27. Nóbrega SR, Libardi CA. Is resistance training to muscular failure necessary? Front Physiol 2016;7(10):10. https://doi.org/10.3389/fphys.2016.00010

28. Kikuchi N, Nakazato K. Low-load bench press and push-up induce similar muscle hypertrophy and strength gain. J Exerc Sci Fit 2017;15(1):37-42. https://doi.org/10.1016/j.jesf.2017.06.003 29. Joy JM, Lowery RP, Oliveira de Souza E, Wilson JM. Elastic bands as a component of periodized resistance training. J Strength Cond Res 2016;30(8):2100-6. https://doi.org/10.1519/ JSC.ob013e3182986bef

30. Turner A, Comfort P. Advanced strength and conditioning: an evidence-based approach. Routledge; 2017.

31. Barbalho M, Coswig VS, Bottaro M, de Lira CAB, Campos MH, Vieira CA et al. "NO LOAD" resistance training increases functional capacity and muscle size in hospitalized female patients: A pilot study. Eur J Transl Myol 2019;29(4):8492. https://doi.org/10.4081/ejtm.2019.8492.

32. Gómez-Tomás C, Chulvi-Medrano I, Carrasco JJ, Alakhdar Y. Effect of a 1-year elastic band resistance exercise program on cardiovascular risk profile in postmenopausal women. Menopause 2018;25(9):1004-10. https://doi.org/10.1097/GME.0000000000001113

33. Winett RA, Ogletree AM. Evidence-based, high-intensity exercise and physical activity for compressing morbidity in older adults: a narrative review. Innov Aging 2019;3(2). https://doi. org/10.1093/geroni/igz020

34. Orange ST, Marshall P, Madden LA, Vince RV. Short-term training and detraining effects of supervised vs. unsupervised resistance exercise in aging adults. J Strength Cond Res 2019;33(10):2733-2742. https://doi.org/10.1519/JSC.0000000000002536

35. Andersen V, Fimland MS, Cumming KT, Vraalsen $\varnothing$, Saeterbakken AH. Explosive resistance training using elastic bands in young female team handball players. Sports Med Int Open 2018;2(6):E171-8. https://doi.org/10.1055/a-0755-7398

36. Mascarin NC, de Lira CAB, Vancini RL, de Castro Pochini A, da Silva AC, Dos Santos Andrade M. Strength Training using elastic bands: improvement of muscle power and throwing performance in young female handball players. J Sport Rehabil 2017;26(3):245-52. https://doi. org $/ 10.1123 /$ jsr.2015-0153

37. Buskard AN, Oh J, Eltoukhy M, Brounstein S, Signorile JF. A novel method to determine optimal load in elastic-based power training. J Strength Cond Res 2018;32(9):2401-8. https://doi. org $/ 10.1519 /$ JSC. 0000000000002759

38. Grgic J, Schoenfeld BJ, Davies TB, Lazinica B, Krieger JW, Pedisic Z. Effect of resistance training frequency on gains in muscular strength: a systematic review and meta-analysis. Sports Med 2018;48(5):1207-20. https://doi.org/10.1007/s40279-018-0872-x

39. Schoenfeld BJ, Grgic J, Krieger J. How many times per week should a muscle be trained to maximize muscle hypertrophy? A systematic review and meta-analysis of studies examining the effects of resistance training frequency. J Sports Sci 2019;37(11):1286-95. https://doi.org/10.108 0/02640414.2018.1555906

40. Morton RW, McGlory C, Phillips SM. Nutritional interventions to augment resistance training-induced skeletal muscle hypertrophy. Front Physiol 2015;6:245. https://doi.org/10.3389/ fphys.2015.00245

41. Stokes T, Hector AJ, Morton RW, McGlory C, Phillips SM. Recent perspectives regarding the role of dietary protein for the promotion of muscle hypertrophy with resistance exercise training. Nutrients 2018;10(2):E180. https://doi.org/10.3390/nu10020180 